Check for updates

Cite this: RSC Adv., 2018, 8, 32533

Accepted 15th September 2018

DOI: $10.1039 / \mathrm{c} 8 \mathrm{ra07027j}$

rsc.li/rsc-advances

\section{Phosphorus pentoxide/metal chloride mediated efficient and facile catalytic conversion of fructose into 5-hydroxymethylfurfural $\dagger$}

\author{
Songyan Jia, (D) *a Xinjun $\mathrm{He}^{a}{ }^{a}$ Jiao Ma, ${ }^{a}$ Zhanwei Xu, ${ }^{b}$ Kangjun Wang ${ }^{a}$ \\ and Z. Conrad Zhang (D) *b
}

Phosphorus pentoxide $\left(\mathrm{P}_{2} \mathrm{O}_{5}\right)$ /metal chloride mixtures could significantly improve 5-HMF yield and selectivity for the catalytic conversion of fructose under mild conditions, whereas neither $\mathrm{P}_{2} \mathrm{O}_{5}$ nor tested metal chloride alone gave reasonable performances. A maximum 5 - HMF yield of $75 \%$ with $\sim 85 \%$ selectivity could be achieved within $30 \mathrm{~min}$ at $80^{\circ} \mathrm{C}$.
Utilization of alternative energy sources has emerged as an important worldwide strategy to compensate for depleting fossil fuels. Renewable biomass has attracted extensive attention for the production of biobased chemicals over the last decades..$^{1-4} 5$ Hydroxymethylfurfural (5-HMF) is a representative platform compound derived from carbohydrates. ${ }^{5-7} 5$-HMF can be converted into high value-added chemicals by a variety of processes, with the potential of sustainable development. ${ }^{8-11}$

Currently, 5-HMF is primarily produced through conversion of carbohydrates such as fructose, glucose and oligosaccharides. Among these carbohydrates, fructose is the most reactive feedstock and extensively investigated, although glucose is more abundant in nature..$^{5-9}$ Indeed, the conversion of glucose into 5-HMF is considered as a two-step tandem reaction including "isomerization of glucose into fructose" and "dehydration of fructose into 5-HMF". ${ }^{12-14}$ Therefore, efficient conversion of fructose is an essential step for 5-HMF production.

Pioneering works have demonstrated that fructose can be effectively converted into 5-HMF with mineral acids, metal salts, zeolites and other functionalized acidic materials. ${ }^{15-19} \mathrm{~A}$ number of reaction media such as polar organic solvents, ionic liquids and water-organic solvent biphasic solvents have been shown to be benign to the conversion of fructose. ${ }^{20-22}$ However, most reported technologies still face some questions as follows: (1) high temperatures at $150-180{ }^{\circ} \mathrm{C}$ are necessary for biphasic systems; (2) reaction temperature can be decreased to around

${ }^{a}$ College of Chemical Engineering, Shenyang University of Chemical Technology, Shenyang, Liaoning, 110142, China. E-mail: jiasongyan@126.com; Tel: +86-24-89386342

${ }^{b}$ State Key Laboratory of Catalysis, Dalian National Laboratory for Clean Energy, Dalian Institute of Chemical Physics, Chinese Academy of Sciences, Dalian, Liaoning, 116023, China. E-mail: zczhang@yahoo.com; Tel: +86-411-84379462

$\dagger$ Electronic supplementary information (ESI) available. See DOI: $10.1039 / \mathrm{c} 8 \mathrm{ra0} 07027 \mathrm{j}$
$120{ }^{\circ} \mathrm{C}$ in polar organic solvents, while reaction time still remains 1-3 h; (3) the viscosity of ionic liquid limits its application at low temperatures; (4) cost and time for the preparation of some functionalized materials is an issue. Therefore, efficient and facile conversion of fructose under mild conditions remains an important research subject.

The conversion of fructose into 5-HMF at low temperatures $\left(25-50{ }^{\circ} \mathrm{C}\right)$ had been mainly achieved in ionic liquid based media, in which 5 -HMF yields of $\sim 40-80 \%$ were available. However, relatively long reaction time (e.g. 4-12 h) was mandatory for a reasonable 5-HMF yield. ${ }^{23-26}$ In addition, a common ionic liquid, 1-butyl-3-methylimidazolium chloride, was used as a solvent in the works above. This ionic liquid has a melting point at $\sim 70{ }^{\circ} \mathrm{C},{ }^{25}$ indicating that additional operations are necessary to lower the viscosity at low temperatures. A solvent with low viscosity is more desirable for fructose conversion under mild conditions.

In this work, we investigated approaches to achieve the effective conversion of fructose into 5-HMF under mild conditions. Dimethyl sulfoxide (DMSO) was used as a solvent due to its ability of suppressing side reactions. ${ }^{27} \mathrm{~A}$ variety of metal chlorides were preliminarily employed as the catalysts because they could efficiently catalyze the production of 5-HMF from fructose in an ionic liquid at moderate temperatures as previously reported. ${ }^{12}$

The conversion of fructose was first evaluated over different metal chloride catalysts in DMSO at $80^{\circ} \mathrm{C}$ for $30 \mathrm{~min}$. As shown in Fig. 1, the reaction with $\mathrm{SnCl}_{4} \cdot 5 \mathrm{H}_{2} \mathrm{O}$ showed a maximum conversion of $43 \%$, while the 5-HMF yield and selectivity reached only $14 \%$ and $33 \%$, respectively. Although $\mathrm{CrCl}_{3} \cdot 6 \mathrm{H}_{2} \mathrm{O}$ and $\mathrm{AlCl}_{3} \cdot 6 \mathrm{H}_{2} \mathrm{O}$ resulted in a little amount of 5-HMF, most catalysts did not actually work at all, implying that more severe conditions were necessary for 5-HMF synthesis with the metal chlorides alone. According to literatures, fructose undergoes acid catalyzed dehydration to yield $5-\mathrm{HMF}^{28-30}$ The three metal 


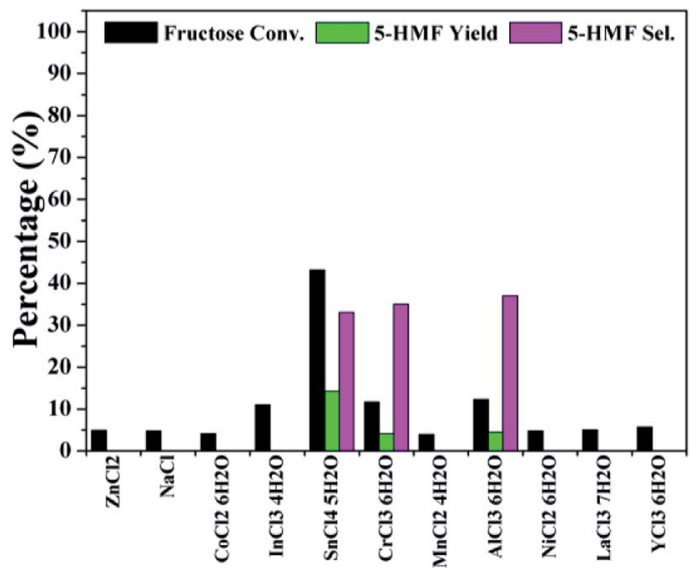

Fig. 1 Screening tests on the conversion of fructose into 5-HMF with metal chlorides as catalysts (reaction conditions: fructose $60 \mathrm{mg}$; metal chloride $10 \mathrm{~mol} \%$ to fructose; DMSO $1 \mathrm{~mL} ; 80{ }^{\circ} \mathrm{C} ; 30 \mathrm{~min}$ ).

salts, $\mathrm{SnCl}_{4} \cdot 5 \mathrm{H}_{2} \mathrm{O}, \mathrm{CrCl}_{3} \cdot 6 \mathrm{H}_{2} \mathrm{O}$ and $\mathrm{AlCl}_{3} \cdot 6 \mathrm{H}_{2} \mathrm{O}$, may be more acidic than other tested metal salts in solutions ${ }^{31}$ which lead to the formation of 5-HMF.

As discussed above, the production of 5-HMF undergoes acid catalyzed dehydration of fructose. ${ }^{28-30}$ Efforts should be put on acid catalysis as well as water removal. Phosphorus pentoxide $\left(\mathrm{P}_{2} \mathrm{O}_{5}\right)$ as an anhydride is acidic and hygroscopic, which is potentially appropriate for the dehydration of fructose. Based on that, $\mathrm{P}_{2} \mathrm{O}_{5}$ was also investigated as a catalyst in this work. As seen in Fig. 2, $\mathrm{P}_{2} \mathrm{O}_{5}$ showed a superior activity to $\mathrm{SnCl}_{4} \cdot 5 \mathrm{H}_{2} \mathrm{O}$ alone with 5-HMF yield and selectivity of $21 \%$ and $57 \%$, respectively, possibly because $\mathrm{P}_{2} \mathrm{O}_{5}$ could provide acidity and/or absorb the in situ formed water. ${ }^{32,33}$ However, higher $\mathrm{P}_{2} \mathrm{O}_{5}$ loadings did not increase the 5-HMF yield much (Fig. S1 $\dagger$ ). The slightly decreased 5-HMF selectivity demonstrated that more side reactions occurred. Unexpectedly, both 5-HMF yield and selectivity were significantly improved when using mixtures of

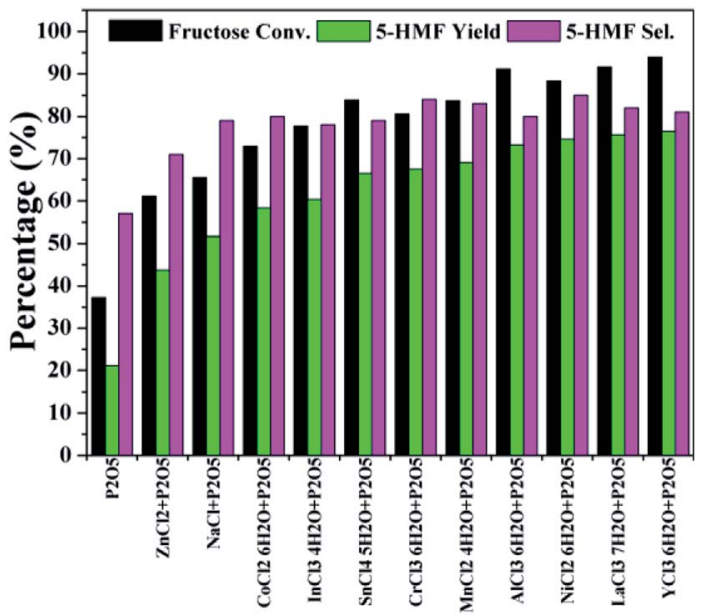

Fig. 2 Conversion of fructose into 5-HMF with mixtures of $\mathrm{P}_{2} \mathrm{O}_{5}$ and metal chloride as catalysts (reaction conditions: fructose $60 \mathrm{mg} ; \mathrm{P}_{2} \mathrm{O}_{5}$ $10 \mathrm{~mol} \%$ to fructose; metal chloride $10 \mathrm{~mol} \%$ to fructose; DMSO $1 \mathrm{~mL}$; $\left.80^{\circ} \mathrm{C} ; 30 \mathrm{~min}\right)$.

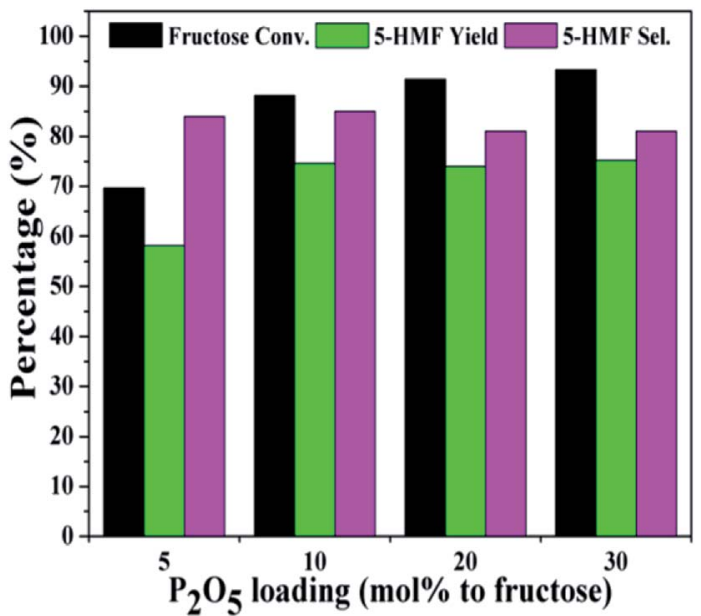

Fig. 3 Effect of $\mathrm{P}_{2} \mathrm{O}_{5}$ loadings on the conversion of fructose with a constant loading of $\mathrm{NiCl}_{2} \cdot 6 \mathrm{H}_{2} \mathrm{O}$ (reaction conditions: fructose $60 \mathrm{mg} ; \mathrm{NiCl}_{2} \cdot 6 \mathrm{H}_{2} \mathrm{O} 10 \mathrm{~mol} \%$ to fructose; DMSO $1 \mathrm{~mL} ; 80{ }^{\circ} \mathrm{C} ; 30 \mathrm{~min}$ ).

$\mathrm{P}_{2} \mathrm{O}_{5}$ and tested metal chloride as catalysts (Fig. 2). The 5-HMF selectivity stayed at about $80 \%$ in the presence of $\mathrm{P}_{2} \mathrm{O}_{5}$ accompanied by most metal chlorides except $\mathrm{ZnCl}_{2}$. Analysis of products showed that no or only trace amount of rehydration products such as levulinic acid were produced in the above reactions (Fig. S2 $\uparrow$ ). In consideration of reaction performance and catalyst cost, $\mathrm{NiCl}_{2} \cdot 6 \mathrm{H}_{2} \mathrm{O}$ was selected as a representative chloride for subsequent investigations.

Fig. 3 and 4 showed the effect of catalyst compositions on the conversion of fructose. The loading of either $\mathrm{NiCl}_{2} \cdot 6 \mathrm{H}_{2} \mathrm{O}$ or $\mathrm{P}_{2} \mathrm{O}_{5}$ was set to be constant for examination. A slightly decreased 5-HMF yield was observed when 5 mol\% $\mathrm{P}_{2} \mathrm{O}_{5}$ was added. The reaction performance remained basically unchanged with increasing $\mathrm{P}_{2} \mathrm{O}_{5}$ loading. In addition, tuning the loading of $\mathrm{NiCl}_{2} \cdot 6 \mathrm{H}_{2} \mathrm{O}$ did not obviously affect the conversion. The above results demonstrated the importance of synergistic effect between $\mathrm{P}_{2} \mathrm{O}_{5}$ and metal chlorides. However,

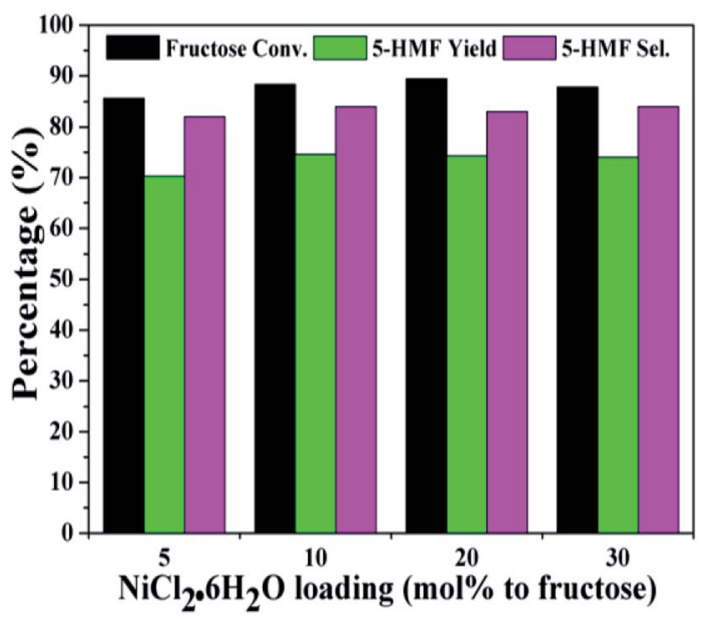

Fig. 4 Effect of $\mathrm{NiCl}_{2} \cdot 6 \mathrm{H}_{2} \mathrm{O}$ loadings on the conversion of fructose with a constant loading of $\mathrm{P}_{2} \mathrm{O}_{5}$ (reaction conditions: fructose $60 \mathrm{mg}$; $\mathrm{P}_{2} \mathrm{O}_{5} 10 \mathrm{~mol} \%$ to fructose; DMSO $1 \mathrm{~mL} ; 80{ }^{\circ} \mathrm{C}$; $30 \mathrm{~min}$ ). 
Table 1 Results on the effect of anions of nickel salts on the conversion of fructose ${ }^{a}$

\begin{tabular}{lllll}
\hline Entry & Catalyst & $\begin{array}{l}\text { Fructose } \\
\text { conv. (\%) }\end{array}$ & $\begin{array}{l}\text { 5-HMF } \\
\text { yield (\%) }\end{array}$ & $\begin{array}{l}\text { 5-HMF } \\
\text { sel. (\%) }\end{array}$ \\
\hline 1 & $\mathrm{P}_{2} \mathrm{O}_{5}$ & 37 & 21 & 57 \\
2 & $\mathrm{P}_{2} \mathrm{O}_{5}+\mathrm{NiCl}_{2} \cdot 6 \mathrm{H}_{2} \mathrm{O}$ & 88 & 75 & 85 \\
3 & $\mathrm{P}_{2} \mathrm{O}_{5}+\mathrm{Ni}\left(\mathrm{NO}_{3}\right)_{2} \cdot 6 \mathrm{H}_{2} \mathrm{O}$ & 65 & 46 & 71 \\
4 & $\mathrm{P}_{2} \mathrm{O}_{5}+\mathrm{NiSO}_{4} \cdot 6 \mathrm{H}_{2} \mathrm{O}$ & 47 & 33 & 70
\end{tabular}

${ }^{a}$ Reaction conditions: fructose $60 \mathrm{mg} ; \mathrm{P}_{2} \mathrm{O}_{5} 10 \mathrm{~mol} \%$ to fructose; $\mathrm{Ni}$ fraction $10 \mathrm{~mol} \%$ to fructose; DMSO $1 \mathrm{~mL} ; 80{ }^{\circ} \mathrm{C} ; 30 \mathrm{~min}$.

the reactivity could not be simply correlated with the catalyst compositions. The loadings of $\mathrm{P}_{2} \mathrm{O}_{5}$ and $\mathrm{NiCl}_{2} \cdot 6 \mathrm{H}_{2} \mathrm{O}$ were set to be $10 \mathrm{~mol} \%$ (to fructose) for further studies as a better 5-HMF yield was obtained at this catalyst composition.

The effect of anions of nickel salts on the conversion of fructose was then investigated. As seen in Table 1 (entries 2-4), the reactions with $\mathrm{NiCl}_{2} \cdot 6 \mathrm{H}_{2} \mathrm{O}, \mathrm{Ni}\left(\mathrm{NO}_{3}\right)_{2} \cdot 6 \mathrm{H}_{2} \mathrm{O}$ and $\mathrm{NiSO}_{4}$ $\cdot 6 \mathrm{H}_{2} \mathrm{O}$ exhibited different performances although they all showed improved 5-HMF yield and selectivity compared to the one with $\mathrm{P}_{2} \mathrm{O}_{5}$ alone. As reported, the production of 5-HMF from fructose underwent a 2-deoxy-2-halo intermediate, which was through a oxocarbenium precursor followed by the nucleophilic attack by a halide ion. ${ }^{34}$ It is proposed that fructose underwent such a mechanism as well in this work, accounting for the performance in the presence of $\mathrm{NiCl}_{2} \cdot 6 \mathrm{H}_{2} \mathrm{O} \cdot \mathrm{Ni}\left(\mathrm{NO}_{3}\right)_{2} \cdot 6 \mathrm{H}_{2} \mathrm{O}$ and $\mathrm{NiSO}_{4} \cdot 6 \mathrm{H}_{2} \mathrm{O}$ showed decreased activities probably because of the higher steric hindrance of nitrate and sulfate anions. Moreover, the reactions with different chromium salts further demonstrated the similar effect of the anions (Table $\mathrm{S} 1 \dagger$ ).

Highly concentrated conversion process is more desirable, since using dilute solutions for biomass refinery may limit the efficacy. Fig. $\mathrm{S} 3 \uparrow$ illustrated the effect of initial fructose loading on the reaction performance. When a less amount of fructose (40 mg) was added, slightly higher 5-HMF yield (77\%) and selectivity (88\%) was obtained than that with $60 \mathrm{mg}$ of fructose, which was attributed to the stabilization of 5-HMF by sufficient solvation effect of DMSO. ${ }^{35}$ However, increasing fructose loading may result in more byproducts and humins. These compounds could be formed by 5-HMF self-condensation or coupling with other compounds, ${ }^{36,37}$ leading to decreased 5HMF yield and selectivity.

To get an optimized 5-HMF yield, the conversion of fructose was examined as a function of time at different temperatures (Fig. 5). The reaction could proceed steadily at $70{ }^{\circ} \mathrm{C}$, while a relatively long time up to $90 \mathrm{~min}$ was required to obtain a reasonable 5-HMF yield. Since the production of 5-HMF from fructose is mainly endothermic, ${ }^{38,39}$ it is expected that elevating temperatures lead to fast reaction rate and improved reaction performance. The conversion was almost completed within $30 \mathrm{~min}$ at $80{ }^{\circ} \mathrm{C}$, and the time could be shortened to $15 \mathrm{~min}$ at $90{ }^{\circ} \mathrm{C}$. A maximum 5 - HMF yield of $\sim 80 \%$ was achievable under such mild conditions.

Preliminary scaling-up tests were also carried out. After $30 \mathrm{~min}$ at $80^{\circ} \mathrm{C}$, a 5 - HMF yield of $74 \%$ with about $90 \%$ fructose
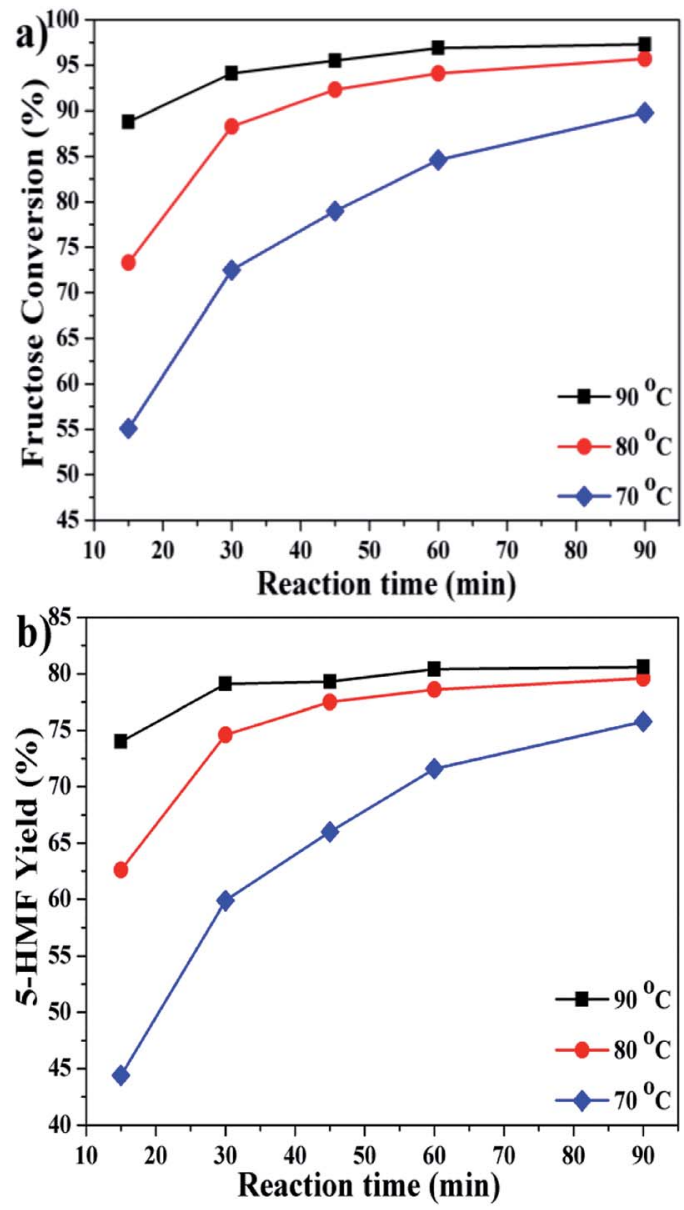

Fig. 5 Effect of reaction temperature and time on the conversion of fructose (reaction conditions: fructose $60 \mathrm{mg} ; \mathrm{P}_{2} \mathrm{O}_{5} 10 \mathrm{~mol} \%$ to fructose; $\mathrm{NiCl}_{2} \cdot 6 \mathrm{H}_{2} \mathrm{O} 10 \mathrm{~mol} \%$ to fructose; DMSO $1 \mathrm{~mL}$ ).

conversion was achieved from 5-fold and 10-fold scaling-up tests, respectively, demonstrating the potential for a large scale production.

Inulin is a kind of fructan material, which can be obtained from natural biomass such as Jerusalem artichoke and chicory. Table S $2 \uparrow$ presented the conversion of inulin in the studied system. 5-HMF with a yield of $\sim 45 \%$ was facilely produced at $80{ }^{\circ} \mathrm{C}$, and elevating reaction temperature can accelerate the formation of 5-HMF as discussed above.

Glucose is of high abundance in nature, and therefore has a great potential for 5-HMF synthesis. ${ }^{5-9}$ It is generally difficult to convert glucose into 5-HMF because the stability of six membered pyran ring of glucose limits its conversion. ${ }^{12}$ It is accepted that glucose should be first isomerized into fructose prior to the production of 5-HMF. ${ }^{12-14}$ In order to get a reasonable yield of 5-HMF, the conversion of glucose was investigated at $100{ }^{\circ} \mathrm{C}$. However, as seen in Table $\mathrm{S} 3, \dagger$ the studied system did not work for the production of 5-HMF although the conversion could be improved with mixtures of $\mathrm{P}_{2} \mathrm{O}_{5}$ and metal chlorides. The tiny yield of 5-HMF indicated that metal chlorides such as $\mathrm{CrCl}_{3} \cdot 6 \mathrm{H}_{2} \mathrm{O}$ and $\mathrm{AlCl}_{3} \cdot 6 \mathrm{H}_{2} \mathrm{O}$ did not enable the isomerization of glucose into fructose under tested conditions. 
Table 2 Results on the control experiments ${ }^{a}$

\begin{tabular}{lllc}
\hline Entry & Catalyst & $\begin{array}{l}\text { Fructose } \\
\text { conv. (\%) }\end{array}$ & $\begin{array}{l}\text { 5-HMF } \\
\text { yield (\%) }\end{array}$ \\
\hline 1 & $\mathrm{P}_{2} \mathrm{O}_{5}$ & 37 & 21 \\
2 & $\mathrm{P}_{2} \mathrm{O}_{5}+\mathrm{NiCl}_{2} \cdot 6 \mathrm{H}_{2} \mathrm{O}$ & 88 & 75 \\
$3^{b}$ & $\mathrm{P}_{2} \mathrm{O}_{5}$ & 33 & 18 \\
$4^{c}$ & $\mathrm{P}_{2} \mathrm{O}_{5}$ & 29 & 16 \\
$5^{d}$ & $\mathrm{H}_{3} \mathrm{PO}_{4}$ & 6 & 2 \\
$6^{d}$ & $\mathrm{H}_{3} \mathrm{PO}_{4}+\mathrm{NiCl}_{2} \cdot 6 \mathrm{H}_{2} \mathrm{O}$ & 9 & 3 \\
7 & $\mathrm{P}_{2} \mathrm{O}_{5}+\mathrm{NaCl}$ & 66 & 52 \\
$8^{d}$ & $\mathrm{NaH}_{2} \mathrm{PO}_{4}$ & 4 & 0 \\
$9^{d}$ & $\mathrm{Na}_{2} \mathrm{HPO}_{4}$ & 5 & 0
\end{tabular}

${ }^{a}$ Reaction conditions: fructose $60 \mathrm{mg} ; \mathrm{P}_{2} \mathrm{O}_{5} 10 \mathrm{~mol} \%$ to fructose; metal chloride $10 \mathrm{~mol} \%$ to fructose; DMSO $1 \mathrm{~mL} ; 80^{\circ} \mathrm{C} ; 30$ min. ${ }^{b} 4 \mu \mathrm{L}$ of $\mathrm{H}_{2} \mathrm{O}$ ( $67 \mathrm{~mol} \%$ to fructose) was added. ${ }^{c} 8 \mu \mathrm{L}$ of $\mathrm{H}_{2} \mathrm{O}$ was added. ${ }^{d}$ Catalyst $20 \mathrm{~mol} \%$ to fructose (equivalent to the mole of phosphorus in $\mathrm{P}_{2} \mathrm{O}_{5}$ ).

As known, DMSO has a good capacity for dissolving 5-HMF, which may be an issue for the isolation of 5-HMF. Tong et al. gave a strategy for separating 5 -HMF from DMSO system. ${ }^{\mathbf{4}}$ DMSO can be first collected by distillation under reduced pressure. Then, 5-HMF can be isolated by extracting the residue with an appropriate low boiling organic solvent followed by the subsequent distillation of organic solvent.

Finally, a few control experiments were conducted to gain some preliminary mechanistic insights. $\mathrm{P}_{2} \mathrm{O}_{5}$ as an anhydride is expected to produce phosphoric acid $\left(\mathrm{H}_{3} \mathrm{PO}_{4}\right)$ by reacting with water during the dehydration of fructose. To confirm whether $\mathrm{H}_{3} \mathrm{PO}_{4}$ worked for the conversion, water was used as an additive to promote the formation of $\mathrm{H}_{3} \mathrm{PO}_{4}$. As seen in Table 2, a small amount of water indeed suppressed the conversion of fructose (entries1, 3 and 4), indicating that $\mathrm{H}_{3} \mathrm{PO}_{4}$ should not be the actual catalyst. Then, $\mathrm{H}_{3} \mathrm{PO}_{4}$ was employed to instead of $\mathrm{P}_{2} \mathrm{O}_{5}$. The results further demonstrated that $\mathrm{H}_{3} \mathrm{PO}_{4}$ did not work as well as $\mathrm{P}_{2} \mathrm{O}_{5}$ (entries1, 2, 5 and 6). On the other hand, a phosphate could be formed if $\mathrm{P}_{2} \mathrm{O}_{5}$ was converted into $\mathrm{H}_{3} \mathrm{PO}_{4}$ followed by interacting with metal salts in the studied system. However, as shown in entries 7-10, the tested phosphates gave rather inferior performance to that with both $\mathrm{P}_{2} \mathrm{O}_{5}$ and $\mathrm{NaCl}$. Although the mechanism remains unknown, the above investigations demonstrate a synergy effect between $\mathrm{P}_{2} \mathrm{O}_{5}$ and metal salts in the conversion of fructose, which needs further study to elaborate in the future.

\section{Conclusions}

In conclusion, this work demonstrated that $\mathrm{P}_{2} \mathrm{O}_{5} /$ metal chloride mixtures could significantly catalyze the efficient and facile conversion of fructose into 5-HMF under mild conditions. About $75 \%$ of 5 -HMF yield and $85 \%$ of 5 -HMF selectivity could be achieved within only $30 \mathrm{~min}$ at $80^{\circ} \mathrm{C}$. Inulin was also able to be efficiently converted into 5-HMF under such conditions with a yield of $45 \%$. The studied system was pervasive to many metal salts, especially chlorides, leaving a broad room for catalyst design in the future.

\section{Conflicts of interest}

There are no conflicts to declare.

\section{Acknowledgements}

The authors thank for the support from the Natural Science Foundation of Liaoning Province (China) (No. 2015020633), Department of Education of Liaoning Province (China) (No. L2015421), the National Natural Science Foundation of China (No. 21673229, 21721004, 21706255) and the CAS/SAFEA International Partnership Program for Creative Research Teams.

\section{References}

1 R. A. Sheldon, ACS Sustainable Chem. Eng., 2018, 6, 44644480.

2 M. Besson, P. Gallezot and C. Pinel, Chem. Rev., 2014, 114, 1827-1870.

3 P. Y. Dapsens, C. Mondelli and J. Pérez-Ramírez, ACS Catal., 2012, 2, 1487-1499.

4 Z. Zhang and G. W. Huber, Chem. Soc. Rev., 2018, 47, 13511390.

5 P. Zhou and Z. Zhang, Catal. Sci. Technol., 2016, 6, 36943712.

6 B. R. Caes, R. E. Teixeira, K. G. Knapp and R. T. Raines, ACS Sustainable Chem. Eng., 2015, 3, 2591-2605.

7 A. Chinnappan, C. Baskar and H. Kim, RSC Adv., 2016, 6, 63991-64002.

$8 \mathrm{~L}$. Hu, L. Lin, Z. Wu, S. Zhou and S. Liu, Renewable Sustainable Energy Rev., 2017, 74, 230-257.

9 T. Wang, M. W. Nolte and B. H. Shanks, Green Chem., 2014, 16, 548-572.

10 S. Xu, P. Zhou, Z. Zhang, C. Yang, B. Zhang, K. Deng, S. Bottle and H. Zhu, J. Am. Chem. Soc., 2017, 139, 14775-14782.

11 L. Gao, K. Deng, J. Zheng, B. Liu and Z. Zhang, Chem. Eng. J., 2015, 270, 444-449.

12 H. Zhao, J. E. Holladay, H. Brown and Z. C. Zhang, Science, 2007, 316, 1597-1600.

13 Y. Lu, H. Li, J. He, Y. Liu, Z. Wu, D. Hu and S. Yang, RSC Adv., 2016, 6, 12782-12787.

14 H. Xin, T. Zhang, W. Li, M. Su, S. Li, Q. Shao and L. Ma, RSC Adv., 2017, 7, 41546-41551.

15 P. Körner, D. Jung and A. Kruse, Green Chem., 2018, 20, 2231-2241.

16 F. N. D. C. Gomes, F. M. T. Mendes and M. M. V. M. Souza, Catal. Today, 2017, 279, 296-304.

17 X. Zhou, Z. Zhang, B. Liu, Q. Zhou, S. Wang and K. Deng, J. Ind. Eng. Chem., 2014, 20, 644-649.

18 Z. Ma, H. Hu, Z. Sun, W. Fang, J. Zhang, L. Yang, Y. Zhang and L. Wang, ChemSusChem, 2017, 10, 1669-1674.

19 X. Guo, J. Tang, B. Xiang, L. Zhu, H. Yang and C. Hu, ChemCatChem, 2017, 9, 3218-3225.

20 G. Raveendra, M. Surendar and P. S. S. Prasad, New J. Chem., 2017, 41, 8520-8529.

21 Y. Xiao and X. Huang, RSC Adv., 2018, 8, 18784-18791. 
22 A. Pande, P. Niphadkar, K. Pandare and V. Bokade, Energy Fuels, 2018, 32, 3783-3791.

23 Z. Zhang, B. Liu and Z. K. Zhao, Carbohydr. Polym., 2012, 88, 891-895.

24 J. Y. G. Chan and Y. Zhang, ChemSusChem, 2009, 2, 731-734.

25 X. Qi, M. Watanabe, T. M. Aida and R. L. Smith, Jr., ChemSusChem, 2009, 2, 944-946.

26 L. Lai and Y. Zhang, ChemSusChem, 2010, 3, 1257-1259.

27 Y. Román-Leshkov, J. N. Chheda and J. A. Dumesic, Science, 2006, 312, 1933-1937.

28 W. Li, T. Zhang, H. Xin, M. Su, L. Ma, H. Jameel, H. Chang and G. Pei, RSC Adv., 2017, 7, 27682-27688.

29 C. Bispo, K. D. O. Vigier, M. Sardo, N. Bion, L. Mafra, P. Ferreira and F. Jérôme, Catal. Sci. Technol., 2014, 4, 2235-2240.

30 M. J. Antal, Jr. and W. S. L. Mok, Carbohydr. Res., 1990, 199, 91-109.

31 L. Peng, L. Lin, J. Zhang, J. Zhuang, B. Zhang and Y. Gong, Molecules, 2010, 15, 5258-5272.
32 D. Ray, N. Mittal and W. Chung, Carbohydr. Res., 2011, 346, 2145-2148.

33 Y. Yuan, S. Yao, S. Nie and S. Wang, BioResources, 2016, 11, 2381-2392.

34 J. B. Binder and R. T. Raines, J. Am. Chem. Soc., 2009, 131, 1979-1985.

35 G. Tsilomelekis, T. R. Josephson, V. Nikolakis and S. Caratzoulas, ChemSusChem, 2014, 7, 117-126.

36 Z. Cheng, J. L. Everhart, G. Tsilomelekis, V. Nikolakis, B. Saha and D. G. Vlachos, Green Chem., 2018, 20, 997-1006.

37 G. Tsilomelekis, M. J. Orella, Z. Lin, Z. Cheng, W. Zheng, V. Nikolakis and D. G. Vlachos, Green Chem., 2016, 18, 1983-1993.

38 C. Antonetti, D. Licursi, S. Fulignati, G. Valentini and A. M. R Galletti, Catalysts, 2016, 6, 196.

39 R. S. Assary, P. C. Redfern, J. R. Hammond, J. Greeley and L. A. Curtiss, J. Phys. Chem. B, 2010, 114, 9002-9009.

40 X. Tong and Y. Li, ChemSusChem, 2010, 3, 350-355. 